\title{
Perfil de tolerancia al triclosán y detección de los genes MexA, MexC, AcrB y oqxA relacionados con la expresión de bombas de expulsión en aislados clínicos del género Enterobacter aerogenes y Enterobacter cloacae.
}

\author{
Luisa Fernanda Zanguña Fonseca, María Inés Torres Caycedo², Giselle Di Filippo Iriarte ${ }^{3}$
}

\section{RESUMEN}

Introducción. La resistencia a los antimicrobianos y la tolerancia a biocidas está dada por mecanismos comunes, generados por su uso en diferentes ambientes; mecanismos como la expresión de bombas de expulsión presentes en bacterias del género Enterobacter circulantes amenaza la eficacia de los antimicrobianos limitando las opciones de terapia antibiótica. Objetivos: Determinar el perfil de tolerancia al triclosán y detección de genes asociados a bombas de expulsión en aislados clínicos de Enterobacter aerogenes y Enterobacter cloacae. Materiales y Métodos: Se realizó un estudio observacional, descriptivo y de corte transversal, se determinaron perfiles de tolerancia al triclosán por microdilución, de susceptibilidad antimicrobiana, confirmación fenotípica de mecanismos de resistencia, por reacción en cadena de la polimerasa, se identificó la presencia de genes que codifican para bombas de expulsión. Resultados: El 17\% correspondió a Enterobacter cloacae y el 6\% Enterobacter aerogenes. El 93,7\% de los aislados clínicos del género Enterobacter presentó el fenotipo de resistencia BLEE y AmpC. En el 81,3\% de los aislamientos se obtuvo la presencia de al menos un gen relacionado con las expresión de bombas de expulsión, siendo frecuentes MexC y AcrB; no identificó presencia del gen oqxA. Conclusiones: La resistencia a diferentes grupos de antibióticos se identifica en especies de Enterobacter circulante, así la presencia de enzimas BLEE y AmpC, la presencia de genes relacionados con bombas de expulsión y la alta tolerancia al triclosán. Palabras clave: Triclosán, Resistencia, Bombas de expulsión, Genes, Biocida

${ }^{1}$ Empresa Social del Estado Santiago de Tunja, Colombia. ORCID: https://orcid.org/0000-0003-2772-348X

2 Universidad de Boyacá, Tunja, Colombia. ORCID: Colombia. orcid.org/0000-0003-0690-3182

${ }^{3}$ Corporación Universitaria Rafael Nuñez, Colombia. ORCID: https://orcid.org/0000-0002-7289-1653

Correspondencia: Luisa Fernanda Zanguña Fonseca, Dirección: Transversal 0A \# 69 - 50 Barrio suamox, Tunja, Colombia. Teléfono: 745-0000, Extensión: 9201, Correo: Ifzanguna@uniboyaca.edu.co, Celular: 3133029376.

Citar este artículo así:

Luisa Fernanda Zanguña Fonseca1, María Inés Torres Caycedo2, Giselle Di Filippo Iriarte. Perfil de tolerancia al triclosán y detección de los genes MexA, MexC, AcrB y oqxA relacionados con la expresión de bombas de expulsión en aislados clínicos del género Enterobacter aerogenes y Enterobacter cloacae. Revista Investig Salud Univ Boyacá. 2020;7(1): 102-117. doi:https://doi.org/10.24267/23897325.400 
Triclosan tolerance profile and detection of MexA, MexC, AcrB and oqxA genes related to the expression of expulsion pumps in clinical isolates of Enterobacter aerogenes and Enterobacter cloacae.

\begin{abstract}
Introduction. Antimicrobial resistance and tolerance to biocides is given by common mechanisms, generated by the use of antimicrobial and biocidal substances in different environments, these mechanisms such as the expression of expulsion pumps present in bacteria of the Enterobacter genus circulating threatens the efficacy of antimicrobials by limiting antibiotic therapy options.
\end{abstract}

Objective: to determine the triclosan tolerance profile and detection of genes associated with expulsion pumps in clinical isolates of Enterobacter aerogenes and Enterobacter cloacae.

Materials and Methods: An observational, descriptive and the cross-sectional study was performed, triclosan tolerance profiles were determined by microdilution, antimicrobial susceptibility, phenotypic confirmation of resistance mechanisms, by the presence of polymerase chain reaction, the presence of genes that code for expulsion pumps.

Results: The 17\% corresponded to Enterobacter cloacae and 6\% Enterobacter aerogenes. 93.7\% of the clinical isolates of the genus Enterobacter presented the ESBL and AmpC resistance phenotype. In $81.3 \%$ of the isolates, the presence of at least one gene related to the expression of ejection pumps was obtained, with MexC and AcrB being frequent; did not identify the presence of the oqxA gene.

conclusions: The resistance to different groups of antibiotics is identified in circulating Enterobacter species, as well as the presence of ESBL and AmpC enzymes, the presence of genes related to ejection pumps, and high tolerance to triclosan.

Keywords: Triclosan, Resistance, Efflux pump, Genes, Biocide 


\section{Perfil de tolerância ao triclosan e detecção dos genes mexA, mexC, acrB e oqxA relacionados à expressão de bombas de expulsão em isolados clínicos do gênero Enterobacter aerogenes e Enterobacter cloacae}

\section{RESUMO}

Introdução.A resistência antimicrobiana e a tolerância a biocidas esta dada pelos mecanismos comuns gerados pelo uso em diferentes ambientes; mecanismos como a expressão de bombas de expulsão presentes em bactérias do gênero Enterobacter circulantes ameaza a eficácia das antimicrobiana limitando as opções de terapia antibiótica.

Objetivos: Determinar o perfil de tolerância ao triclosan e detecção dos genes asociados a bombas de expulsão em isolados clínicos Enterobacter aerogenes e Enterobacter cloacae.

Materiais e Métodos: Realizou-se um estudo observacional, descritivo e de corte transversal, determinaram-se perfiles de tolerância ao triclosan por microdiluição, de susceptibilidade antimicrobiana, confirmação de mecanismos de resistência fenotípica por reação em cadeia da polimerase, identificou-se a presença de genes que codificam para bombas de expulsão.

Resultados: 17\% correspondeu ao Enterobacter cloacae e 6\% ao Enterobacter aerogenes. 93,7\% em isolados clínicos do gênero Enterobacter presentou o fenótipo de resistência BLEE e AmpC. No 81\% dos isolamentos se obteve a presença de pelo menos um gen relacionado à expressão de bombas de expulsão, sindo frequentes mexC e acrB; não se identificou a presença do gen oqxA.

Conclusões: A resistência de diferentes grupos de antibióticos se identificou em espécies de Enterobacter circulante, assim a presença de enzimas BLEE e AmpC, a presença de genes relacionados com bombas de expulsão e a alta tolerância ao triclosan.

Palavras-Chave: triclosan, resistência, bombas de expulsão, genes, biocida 


\section{INTRODUCCIÓN}

Los biocidas son sustancias sintéticas de origen natural o químico, que son utilizados para la limpieza de superficies. El Triclosán es un derivado del fenol, siendo común encontrarlo como componente de enjuagues orales y cremas dentales, actúa contra bacterias Gram positivas y Gram negativas; su mecanismo de acción se da en la membrana citoplasmática, causando una bacteriólisis $(1,2)$.

Por su parte, Enterobacter es un género de bacterias Gram-negativos, anaeróbicas facultativas, que pertenecen a la familia Enterobacteriaceae, es una bacteria oportunista y multirresistente; su gran capacidad de diseminación se debe a la presencia de proteínas reguladoras de la permeabilidad de su membrana y de la expresión de enzimas detoxificantes que degradan e inactivan los antibióticos, una afinidad de esta especie es la capacidad para formar biopelículas, hasta el momento hay dos especies comunes, Enterobacter aerogenes y Enterobacter cloacae $(2,3)$. La especie Enterobacter cloacae se encuentran ampliamente en la naturaleza, es frecuentemente aislada de muestras clínicas humanas en procesos infecciosos de sistema respiratorio y tracto urinario, por lo cual ha adquirido importancia clínica como bacteria oportunista y surgido como patógeno de infecciones asociadas a la atención en salud de pacientes de cuidados intensivos, especialmente para aquellos con ventilación mecánica (2).
Teniendo en cuenta la resistencia natural y la adquirida, las respuestas bacterianas frente a la acción de antibióticos y biocidas comparten algunas estrategias comunes, se evidencia que las bacterias pueden desarrollar una resistencia emergente a los antibióticos después de la exposición a biocidas, dado por la resistencia cruzada, el cambio fenotípico, la co-resistencia, los cambios en los perfiles de susceptibilidad de poblaciones microbianas, entre otras (4).

El género Enterobacter sp produce una B-lactamasa determinada por genes cromosomales que le confiere una resistencia natural; este tipo de resistencia está relacionada con una enzima del tipo AmpC, la cual se expresa de manera inducible $(3,4)$ y se puede encontrar en todos los aislados clínicos silvestres $(5,6)$, siendo este tipo de fenotipo resistente a ampicilina, cefalotina $y$ cefoxitina $(7,8)$. El Enterobacter cloacae se considera intrínsecamente resistente a las aminopenicilinas, cefalosporinas de primera generación y cefoxitina debido a la presencia de $\beta$-lactamasas del tipo Ampc, lo que implica susceptibilidad variable a cefalosporinas de tercera y cuarta generación $(9,10)$. De otra parte, en este género bacteriano se identifica el mecanismo de bombas de eflujo de la familia RND -Resistencia, Nodulación, División celular- $(11,12)$, como un paso evolutivo frente al presión de los antibióticos que contribuye a la resistencia intrínseca adquirida y que expresa fenotipos de multiresistencia antibiótica y tolerancia a sustancias biocidas $(13,14)$. 
El propósito de este estudio fue determinar los perfiles de tolerancia al Triclosán, perfiles de resistencia antibiótica y presencia de genes relacionados con la expresión de bombas de expulsión, en aislamientos de Enterobacter aerogenes y Enterobacter cloacae, dado que en el medio se observa la circulación de Enterobacter con resistencia antibiótica en las cuales no se ha explorado aún su respuesta frente al triclosán (15).

\section{MATERIALES Y MÉTODOS}

Se llevó a cabo un estudio observacional, descriptivo y de corte transversal. Se realizó un análisis univariado para determinar frecuencias de susceptibilidad o resistencia a los antibióticos utilizados en los perfiles de susceptibilidad antibióti$\mathrm{ca}$, frecuencia de respuesta a las concentraciones del biocida utilizadas en el perfil de tolerancia al triclosán y de la presencia de genes de bombas de expulsión en 12 aislamientos de Enterobacter cloacae y 4 de Enterobacter aerogenes, provenientes de 71 aislados de muestras clínicas de una IPS en el departamento de Boyacá. Se determinó la frecuencia de los perfiles de resistencia, de la tolerancia a diferentes concentraciones de triclosán y de genes relacionados con la expresión de bombas de expulsión. El trabajo fue avalado por comités de ética institucionales.

Aislamiento e identificación: Para la identificación de los aislamientos de Enterobacter sp. se realizó mediante el equipo Phoenix 100 con sistema de paneles para identificación de género, especie y se realizó pruebas de susceptibilidad por CIM -Concentración Mínima Inhibitoria- utilizando panel de antibióticos que incluyó las cefalosporinas de 1, 2, 3 y 4, carbapenémicos, amikacina, ampicilina sulbactam, ciprofloxacina, piperacilina tazobactam, Tigecilcina, trimetropin-sulfametoxazol. Estos aislamientos se conservaron en BHI- glicerol $20 \%$ a $-80^{\circ} \mathrm{C}$.

Reactivación: Se realizó reactivación de los asilados en caldo BHI (BD Brain Heart Infusión) a $37^{\circ} \mathrm{C}$ por 24 horas (overnight) en agitación.

\section{Confirmación fenotípica de mecanismos de re-} sistencia: Se realizó la confirmación de fenotipos de resistencia de los aislados clínicos de bacterianas de Enterobacter sp. siguiendo las normas CLSI 2017.

\section{Ensayo y montaje de tolerancia al triclosán: El} ensayo se realizó con una concentración estándar de la bacteria $1 / 10$, tomando $100 \mu \mathrm{l}$ del cultivo overnight y $900 \mu \mathrm{l}$ solución salina $0.85 \%$. Para la preparación de las diluciones del triclosán se partió de una concentración inicial Ci utilizando alcohol etílico $96^{\circ}$, las concentraciones utilizadas fueron C1 $(1 \%)$, C2 $(0.25 \%)$, C3 $(0.025 \%)$, C4 $(0.0025 \%)$ y C5 $(0.00025 \%)$, estas se prepararon en caldo BHI. El montaje se realizó en microplacas de 96 pocillos, se dispenso en los pozos las di- 
ferentes concentraciones de Triclosan y se utilizó control de medio de cultivo $\mathrm{BHI}$, control de crecimiento bacteriano (medio $\mathrm{BHI}$ e inóculo), control de biocida (cada dilución); la microplacas se incubaron a $37^{\circ} \mathrm{C}$ por 24 horas. La lectura se realizó en el equipo ImarK® Biorad a una absorbancia $595 \mathrm{~nm}$ y la lectura de tolerancia se determinó con lectura de pozo biocida + inóculo y lectura control de biocida (16).

Extracción de ADN: Se utilizó el kit de extracción Wizard $\AA$ Genomic DNA purificación de Promega, siguiendo el protocolo 003 Extracción de ADN (17). Se determino la concentración del ADN Nanodrop NANO Maestrogen ${ }^{\circledR}$.

Detección de genes de bombas de expulsión: Los genes evaluados por PCR convencional fueron oqxA, AcrB, Mex C y Mex A. Se estandarizó el protocolo de $\mathrm{PCR}$ para cada gen y se utilizó termociclador LOMBOCON ${ }^{\circledR}$. En la tabla 1 se muestra los primeros utilizados en el estudio y el tamaño de banda de cada gen de resistencia (Tabla 1).

Electroforesis: Para los genes AcrB y Mex $C$ se realizó la electroforesis en gel de agarosa al $2 \%$ y para el gen Mex $A$ se realizó en gel de agarosa al $1.5 \%$. Los parámetros de corrida fueron de 45 minutos a 50 voltios.
Tabla 1. Primers utilizados en el estudio; tamaño de banda y temperatura de anillamiento.

\begin{tabular}{|c|c|c|c|c|}
\hline Gen & Secuencia & $\begin{array}{c}\text { Tamaño } \\
\text { de la } \\
\text { banda }\end{array}$ & $\begin{array}{l}\text { Tm } \\
\text { (c) }\end{array}$ & Referencia \\
\hline $\operatorname{oqx} A$ & $\begin{array}{l}\text { F 5'GACAGCGTC- } \\
\text { GCACAGAATG 3' } \\
\text { R 5'GGAGACGAG- } \\
\text { GTTGGTATGGA 3' }\end{array}$ & 339 & $\begin{array}{c}59.5 \\
{ }^{\circ} \mathrm{C}\end{array}$ & (18) \\
\hline AcrB & $\begin{array}{c}\text { F 5' GGTCGATTCC- } \\
\text { GTTCTCCGTTA -3' } \\
\text { R 5'- CTACCTG- } \\
\text { GAAGTAAACGT- } \\
\text { CATTGGT -3' }\end{array}$ & 107 & $\begin{array}{c}61.3 \\
{ }^{\circ} \mathrm{C}\end{array}$ & (19) \\
\hline MexA & $\begin{array}{c}\text { F 5’ CTGGAGGAC- } \\
\text { GGTAGCCAATA -3' } \\
\text { R 5'- GACG- } \\
\text { GAAACCTCGGA- } \\
\text { GAAT -3' }\end{array}$ & 60 & $\begin{array}{c}60.5 \\
{ }^{\circ} \mathrm{C}\end{array}$ & (20) \\
\hline MexC & $\begin{array}{l}\text { F 5'AGCCAGCAG- } \\
\text { GACTTCGATAC 3' } \\
\text { R 5'CAGTGACC- } \\
\text { GAGGCGTAGC 3' }\end{array}$ & 118 & $\begin{array}{c}60.7 \\
{ }^{\circ} \mathrm{C}\end{array}$ & $(2,21)$ \\
\hline
\end{tabular}

Fuente: El estudio

\section{RESULTADOS}

De 71 aislamientos clínicos de Gram negativas, se trabajó con 16 que se identificaron en el género Enterobacter, las especies fueron 12 aislados de Enterobacter cloacae, (75\%) y 4 de Enterobater aerogenes (25\%). 


\section{Perfiles de susceptibilidad de los aislados clínicos en estudio}

Los 16 aislamientos de Enterobacter sp mostraron en los perfiles de susceptibilidad antibiótica que fueron sensibles a carbapenémicos, aminoglucósidos, fluoroquinolonas y cefalosporinas de $3^{\circ} \mathrm{y}$ $4^{\circ}$ generación. Los grupos de antibióticos en los que presentan resistencia son las penicilinas, y las cefalosporinas de 1 y 2 generación. Se confirmó la presencia de Betalactamasas de espectro extendido (BLEE) y de AmpC. El 93,7\% de los aislados clínicos de Enterobacter sp. presentaron el fenotipo de resistencia BLEE donde el 25\% $(n=4)$ correspondieron a la especie Enterobacter aerogenes y el $68.7 \%(n=11)$ a Enterobacter cloacae. Una cepa de Enterobacter cloacae presento betalactamasas de amplio espectro BLEA; una cepa de Enterobacter aerogenes presento fenotipo de resistencia para KPC. En la gráfica 1 se observa una combinación de perfiles de resistencia entre los tipos BLEE y AMPC predominando en aislados clínicos de Enterobacter cloacae $(n=11)$. (Figura 1)

\section{Perfil de tolerancia al triclosán de los aislados clínicos en estudio}

En relación con el perfil de tolerancia al triclosán todos los aislados clínicos de fueron tolerantes al triclosán en la concentración más baja C5 $(0,00025 \%)$. La mayoría de los aislados clínicos fueron tolerantes hasta la concentración C1 (1\%). El $43,8 \%$ de los aislamientos $(n=7)$ fueron tolerantes hasta esta concentración, el 31,2\% ( $n=5)$ fueron tolerantes hasta la concentración C3 (0,025\%), seguido de un $18,8 \%$ de los aislados clínicos de que fueron tolerantes hasta la C4 $(0,0025 \%)$. Solo 1 cepa fue tolerante al triclosán hasta la C2 (0,25\%).

Figura 1. Perfil de resistencia bacteriana en aislados clínicos del género Enterobacter.

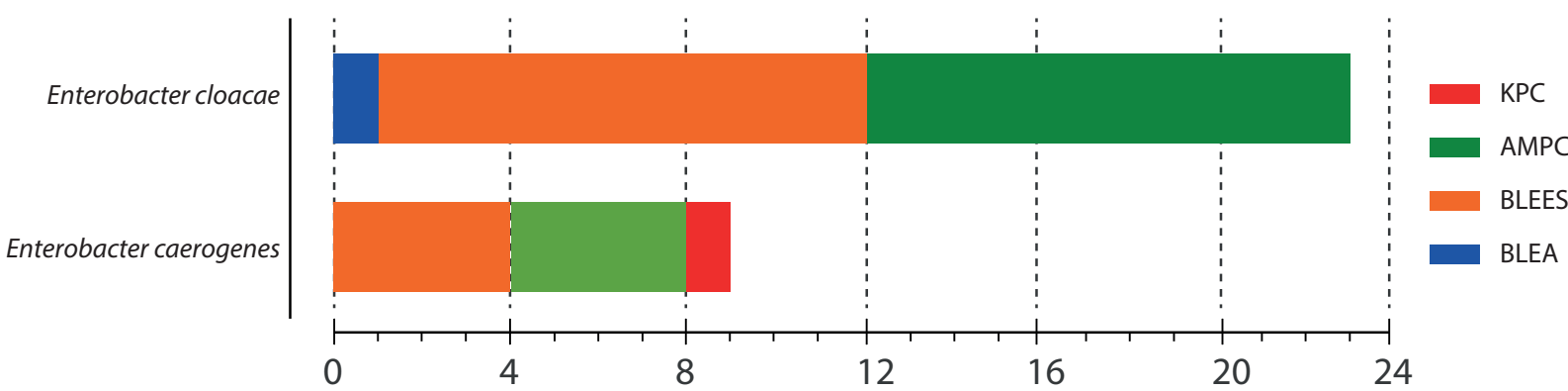

Frecuancia acomulada de fenotipos de resistencia 
Figura 2. Tolerancia al triclosán, aislados clínicos del género Enterobacter. Frecuencia acumulada de las MIC para las cepas estudiadas

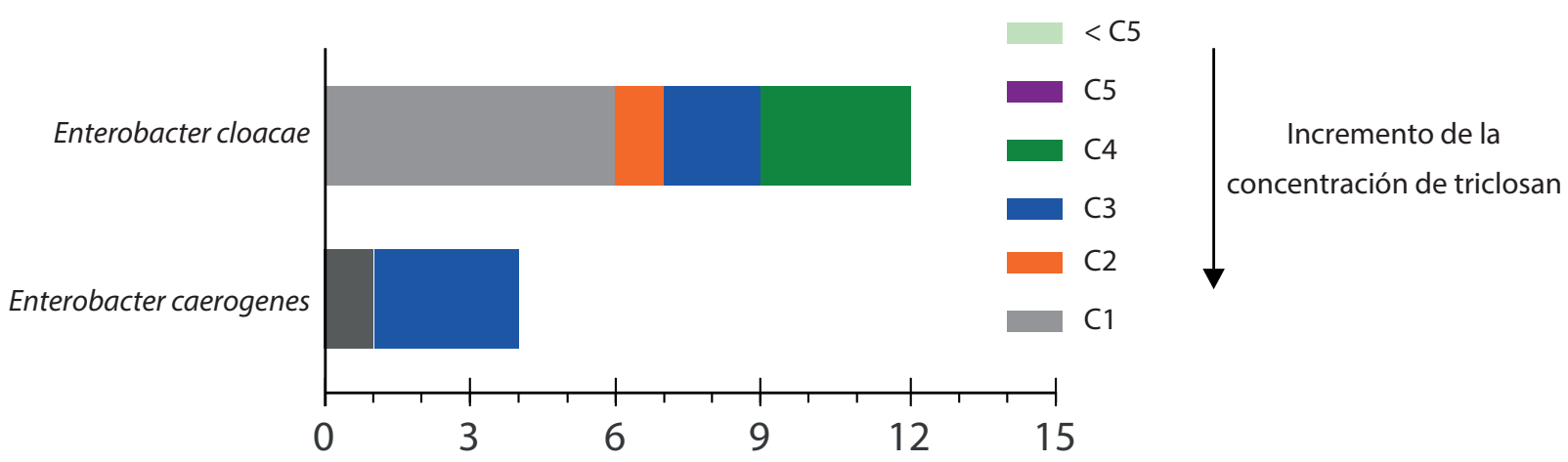

Frecuancia acomulada, MIC de triclosan

*Concentraciones finales de Triclosán: C1: 1\%, C2:0.25 \%, C3:0.025\%, C4:0.0025\%, C5: 0.00025\%

El 50\% $(n=6)$ de los aislados clínicos de Enterobacter cloacae fueron tolerantes hasta la C1 (1\%), mientras que la concentración de triclosán hasta la que toleraron el $75 \%$ de los aislados clínicos de Enterobacter aerogenes fue la C3. En la Figura 2 se muestra la concentración de triclosán a la que fueron sometidas las especies de Enterobacter y el número de aislados clínicos que toleraron hasta determinada concentración.

\section{Genes asociados a bombas de expulsión}

En el $81,3 \%$ de los aislamientos del género Enterobacter se observó la presencia de al menos un gen de resistencia relacionado con la expresión de bombas de expulsión; por especie el 75\% de Enterobacter aerogenes y el 83,3\% de Enterobacter cloacae fueron positivos para la presencia de al menos uno de estos genes. Los genes $M e x C$ y $A c r B$ fueron los más frecuentes en el género estudiado. En el 68,8\% de los aislamientos se encontró la presencia del gen $M e x C$, seguido del gen $A c r B$ con un 56,3\% y el gen MexA con un 25\%; no se observó la presencia del gen oqxA. (Figura 3).

Se observó la presencia de uno o más genes en el mismo microrganismo, en el $75 \%$ de los aislados clínicos de Enterobacter aerogenes se detectó la presencia tanto del gen MexA y el gen $\operatorname{Acr} B$, no se detectó la presencia del gen $M e x C$. En el 
Figura 3. Genes codificantes de bombas de expulsión en aislados clínicos de Enterobacter.

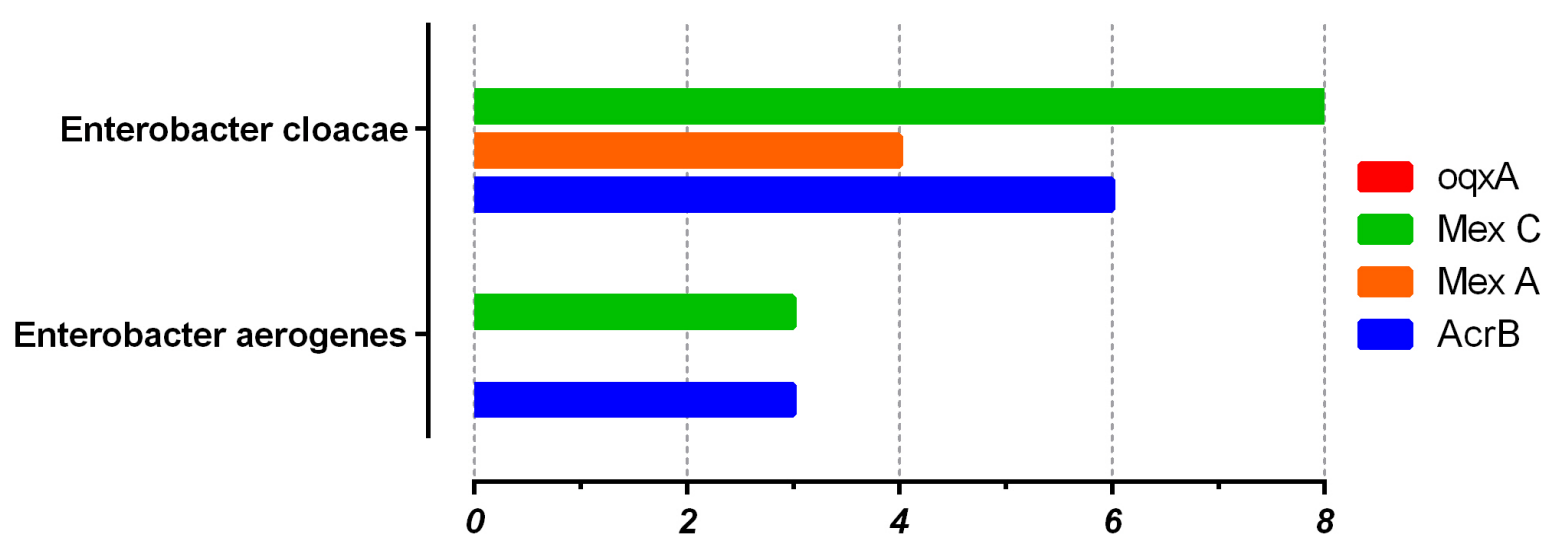

$16,6 \%(n=2)$ de los aislados clínicos de Enterobacter cloacae se observaron los 3 genes acrB, MexA, $M e x C$. El gen con mayor frecuencia fue $M e x C$.

\section{DISCUSIÓN}

En el presente estudio se identificaron 16 aislados clínicos de bacterianas de Enterobacter $s p$ de un total de 71 aislamientos de bacterias Gram negativas provenientes de Infecciones Asociadas a la Atención en Salud (IAAS) correspondiente a un $22,5 \%$, siendo identificadas las especies $E n$ terobacter aerogenesy Enterobacter cloacaeidentificadas en un $25 \%$ y $75 \%$, respectivamente. Este estudio es comparable a un estudio realizado por Jaramillo Gloria en el 2016 donde se aislaron $3,1 \%$ de $E$. cloacae. Sin embargo, la especie de Enterobacter $s p$. más frecuente fue Enterobacter aerogenes $(19,22)$, según los resultados obtenidos presentaron dos mecanismos de resistencia (BLEES y AMPC), evidenciándose resistencia a cefalosporinas de primera y segunda generación y algunas de tercera generación como la Ceftriaxona. De acuerdo al estudio hecho por Tuon FF 2015 y Gonzalez M. 2007 este tipo de mecanismos esta asociado con la resistencia a cefalosporinas de tercera y cuarta generación debido a la sobreexpresión del mecanismo $\operatorname{AmpC}(23,24)$. En el presente estudio se muestra sensibilidad a cefalosporinas de tercera y cuarta generación, al igual que a las familias de los aminoglicósidos y carbapenemicos siendo este resultado un punto a favor para las opciones terapéuticas, en menor proporción se presentan los mecanismos 
Tabla 2. Genes de resistencia asociados a bombas de expulsión en especies de Enterobacter.

\begin{tabular}{|c|c|c|c|c|}
\hline \multirow{2}{*}{ Especie de Enterobacter } & \multicolumn{4}{|c|}{ Genes de resistencia asociados a bombas de expulsión } \\
\hline & $A c r B$ & $\operatorname{MexC}$ & $\operatorname{MexA}$ & $o q x A$ \\
\hline E. aerogenes. 2 Urc. & Presente & Presente & Ausente & Ausente \\
\hline E. aerogenes. $3 U$ rc. & Presente & Presente & Ausente & Ausente \\
\hline E. aerogenes. 4 Ept. & Presente & Presente & Ausente & Ausente \\
\hline E. cloacae. 1 Urc. & Presente & Presente & Presente & Ausente \\
\hline E. cloacae. 2 Ept. & Ausente & Presente & Ausente & Ausente \\
\hline E. cloacae. 3 Ctv. & Presente & Presente & Ausente & Ausente \\
\hline E. cloacae. 4 Shr. & Presente & Presente & Ausente & Ausente \\
\hline E. cloacae. 5Urc. & Ausente & Presente & Ausente & Ausente \\
\hline E. cloacae. 6Ept. & Presente & Presente & Presente & Ausente \\
\hline E. cloacae. 7Urc. & Ausente & Presente & Presente & Ausente \\
\hline E. cloacae. 8Ept. & Ausente & Presente & Presente & Ausente \\
\hline
\end{tabular}

de resistencia tipo BLEA y KPC y se presentan en menor proporción, esto en comparación con lo dicho por BRATU 2005 donde mencionan la extensión de Enterobacteriaceae productoras de KPC, este tipo de mecanismo no solo se encuentra en Klebsiella pneumoniae sino también en E. coli, Enterobacter sp, Citrobacter sp, Serratia sp y otras. Por su parte, Enterobacter sp. productor de KPC se ha descrito en algunas series de Enterobacteriaceae, y recientemente Stalin y Jenkins en el año 2014 publicaron un caso de infección por Enterobacter gergoviae productora de KPC en un paciente inmunosuprimido con desfavorable resultado a pesar de contar con una adecuada terapia (25).

La presencia de genes de resistencia tipo acrB se aprecia en una frecuencia notable en los aislados clínicos de Enterobacter sp.; la bomba de expulsión acrAB-TolC está frecuentemente presente en especies de $E$. coli, esta bomba está compuesta por un transportador activo secundario $\operatorname{acr} B$ ubicado en la membrana interna TolC que funciona como canal en la membrana externa, la proteína $A c r A B$ interacciona con las otras dos proteínas. Esta 
bomba permite el transporte de diferentes compuestos químicos que confiere un perfil amplio de resistencia a antibióticos, fluoroquinolonas entre otros (26) aportando a los perfiles de resistencia en los aislados clínicos de de Enterobacter cloacaese con la demostración de reguladores que influyen en la expresión de genes, como es el caso de la presencia del gen $A c r B$ en un $18 \%$ en Enterobacter aerogenes y un 37\% Enterobacter cloacae (27).

Con respecto al gen MexA y Mex $C$, según estudios como Masuda en el año 2000 y Suarez en el $2018(20,28)$ estos genes se expresan generando resistencia a diversos antibióticos. Esta sobreexpresión de la MexAB-OprM, MexXY-OprM y sistemas de eflujo MexCD-OprJ se demostró en $28 \%$ de los aislamientos bacterianos carbapenémicos no susceptibles, respectivamente, lo que sugiere la contribución de flujo de salida en la resistencia (29). En el estudio hecho por Wołkowicz en el 2016 se puede ver la frecuencia de los genes MexA y MexC en P. aeruginosa (30. Sin embargo, en nuestro estudio se detectó la presencia del gen MexA en el $100 \%$ de los aislamientos de Enterobacter aerogenes y hubo ausencia de este gen en los aislados clínicos de E. cloacae, a diferencia del gen Mex $C$ que se encontró en el $75 \%$ y el $66,6 \%$ de los aislados clínicos de Enterobacter cloacaey $E$. aerogenes, respectivamente.

El gen oqxA es un gen muy frecuente en aislados clínicos de $E$. coli que confiere resistencia antibió- ticos cefalosporinas, aminoglicosidos, en comparación con los aislados clínicos del estudio donde se ve resistencia a cefalosporinas de primera, segunda, tercera y cuarta generación, sin embargo, en los aislados clínico de Enterobacter sp del estudio no se detectó presencia del gen oqxA; según Albornoz E en el 2017 la presencia del gen de resistencia oqxA se ve reflejado en especies de E. coli y P. aeruginosa (31)Mary Ann Liebert, Inc. 2017. This first nationwide study was conducted to analyze the prevalence of plasmid-mediated quinolone resistance (PMQR. Las bacterias suelen tener mecanismos que muestran una amplia especificidad de sustrato siendo capaces de expulsar una variedad de compuestos, estos sistemas de eflujo incluyen una variedad de genes que estimulan la expresión de bombas de eflujo, como el sistema MexA, MexC de $P$. aeruginosa y $A c r B$, oxqA de E. coli.

En general, los mecanismos por los cuales las bacterias son resistentes al triclosán incluyen mutaciones, modificación enzimática y bombas de eflujo que se expresan en respuesta al estrés ejercido por el biocida $(18,19)$. Si relacionamos los resultados de las concentraciones del biocida triclosan vemos una tendencia de tolerancia a las concentraciones expuestas, donde los aislados clínicos de Enterobacter cloacae presentan muestra tolerancia hasta C1(1\%) y para el caso de Enterobacter aerogenesse mantiene hasta C1 (1\%) pero en menor proporción. Con lo anterior, se puede 
evidenciar que los microorganismos evaluados toleraran altas concentraciones del triclosán, biocida utilizado en el ámbito hospitalario, lo que puede estar asociado a la presencia de microorganismos en estas sustancias, a la adquisición de infecciones asociadas al cuidado de la salud y a la diseminación de estos. En este estudio no se obtuvieron aislados clínicos de intolerantes al triclosán, lo que da como resultado que se considere el aumento de las concentraciones del biocida en las soluciones de lavado (32).

En este estudio se pudo demostrar que los aislamientos de Enterobacter aerogenes y Enterobacter clocae toleran diferentes concentraciones del biocida triclosán por encima de $0.0025 \%$, presen$\tan$ genes $A c r B$ y $M e x C$ que codifican bombas de expulsión como mecanismo de resistencia expresado, a la vez que mostraron perfiles de resistencia a antibióticos tipo BLEE y AmpC.

La resistencia a diferentes grupos de antibióticos, la presencia de enzimas BLEE y AmpC, de genes asociados a bombas de expulsión y la tolerancia al triclosán demuestra que en una misma bacteria pueden coexistir diferentes mecanismos de resistencia frente a la acción de los antibióticos utilizados actualmente; igualmente este mecanismo le confiere tolerancia a la acción de antisépticos como el triclosán, utilizado comúnmente en jabones quirúrgicos y elementos higiene personal aplicados en lavado de manos de personal de salud y en pacientes. Este fenómeno se convierte cada día en un reto más para combatir las infecciones asociadas al cuidado de la salud que han aumentado a lo largo de las últimas décadas por los diversos mecanismos de resistencia bacteriana.

\section{DECLARACIÓN DE CONFLICTO DE INTERÉS}

Los autores no declaran ningún conflicto de interés.

\section{FINANCIACIÓN}

La financiación de este proyecto contó con el aporte de la Universidad de Boyacá.

\section{AGRADECIMIENTOS}

Los autores expresan sus agradecimientos a la Universidad de Boyacá y cada uno de los participantes en el estudio.

\section{REFERENCIAS}

1. McCusker MP, Alves Ferreira D, Cooney D, Martins Alves $B$, Fanning $S$, Pagès JM, et al. Modulation of antimicrobial resistance in clinical isolates of Enterobacter aerogenes: A strategy combining antibiotics and chemosensitisers. J Glob Antimicrob Resist 2019;16:187-98. [Internet]. 2019;16:187- 
98. consultado: 11/11/2018 Dispoinible en: https://doi.org/10.1016/j.jgar.2018.10.009

2. Gong G, UmY,ParkTH, WooHM. Completegenome sequence of Enterobacter cloacae GGT036: A furfural tolerant soil bacterium. J Biotechnol. 2015;193:43-4. [Internet]. 2015;193:43-4. consultado: 11/12/2018 Dispoinible en: https:// doi.org/10.1016/j.jbiotec.2014.11.012

3. Ye J, Rensing C, Su J, Zhu YG. From chemical mixtures to antibiotic resistance. J Environ Sci (China). 2017;62:138-44. Internet].20/02/2017 consultado: 11/11/2018 Dispoinible en: https://doi.org/10.1016/j. jes.2017.09.003

4. Paul D, Chakraborty R, Mandal SM. Biocides and health-care agents are more than just antibiotics: Inducing cross to co-resistance in microbes. Ecotoxicol Environ Saf. 2019;174(March):601-10. Internet: [2019], consultado:30/04/2020 Disponible en: https:// doi.org/10.1016/j.ecoenv.2019.02.083

5. Jiménez A, Tijerino A VJ. Mecanismos de resistencia a los antibióticos de importancia clínica en enterobacterias. Cent Nac Ref en Bacteriol Lab Antimicrob [Internet]. 2011;1:15. Internet: [30/05/2011], consultado: 09/02/2018 Disponible en: https://www. inciensa.sa.cr/vigilancia_epidemiologica/
Manuales/Mecanismos de resistencia a los antibioticos en enterobacterias.pdf.pdf

6. Galas M, WHONET R. Grupo Kes. Serv ANTMICROBIANOS. 2000;52. consultado: 05/02/2019, Dispoinible en: http:// antimicrobianos.com.ar/ATB/wp-content/ uploads/2013/02/Grupo-KES-boletin-13.pdf

7. Torres C. Lectura interpretada del antibiograma de cocos grampositivos. Enferm Infecc Microbiol Clin. 2002;20(7):354-64. consultado: 05/02/2019 Dispoinible en: https:// doi.org/10.1016/S0213-005X(02)72815-2

8. CortésJA. Resistenciaenenterobacterias: evolución, enzimas y ambiente. Infectio. 2014;15(3):145-6. consultado: 17/02/2019 Dispoinible en: https:// doi.org/10.1016/S0123-9392(11)70077-7

9. Nastro M, Piazza LM, Saposnik E, García S, Barberis C, Vay C, et al. Resistencia a cefalosporinas de espectro extendido en enterobacterias sin ampc inducible. Evaluación de los nuevos puntos de corte. Rev Argent Microbiol. 2012;44(1):30-5. Internet: [2012], consultado:30/04/2020 Disponible en: http:// www.scielo.org.ar/scielo.php?script=sci_artte xt\&pid=S0325-75412012000100007

10. Garinet $S$, Fihman $V$, Jacquier $H$, Corvec $\mathrm{S}$, Le Monnier A, Guillard T, et al. Elective 
distribution of resistance to beta-lactams among Enterobacter cloacae genetic clusters. J Infect. 2018;77(3):178-82. consultado: 19/02/2019 Dispoinible en: https://doi. org/10.1016/j.jinf.2018.05.005

11. Chevalier J, Mulfinger C, Garnotel E, Nicolas $P$, Davin-Régil $A$, Pagès JM. Identification and evolution of drug efflux pump in clinical Enterobacter aerogenes strains isolated in 1995 and 2003. PLoS One. 2008;3(9):1-8. Internet: [2003], consultado:29/04/2020 Disponible en: https://pdfs.semanticscholar.org/5112/3884be e07f650b340064627c2f45f41773a4.pdf

12. Guérin $F$, Lallement $C$, Isnard $C$, Dhalluin $A$, Cattoir V, Giard J. Landscape of ResistanceNodulation-Cell Division (RND)-Type Efflux Pumps in Enterobacter Cloacae Complex. 2016;60(4):2373-82. Internet: [2016], consultado:28/04/2020. Disponible en: https:// doi.org/10.1128/aac.02840-15

13. Opperman TJ, Nguyen ST. Recent advances toward a molecular mechanism of efflux pump inhibition. Front Microbiol. 2015;6(MAY):116. Internet: [], consultado: 29/04/2020 Disponible en: https://doi.org/10.3389/ fmicb.2015.00421

14. Blanco $P$, Hernando-Amado S, RealesCalderon J, Corona F, Lira F, Alcalde-Rico
$M$, et al. Bacterial Multidrug Efflux Pumps: Much More Than Antibiotic Resistance Determinants. Microorganisms. 2016;4(1):14. Disponible en: https://doi.org/10.3390/ microorganisms4010014

15. Bratu S, Landman D, Alam M, Tolentino E, Quale J, Levine J, et al. Detection of KPC Carbapenem-Hydrolyzing Enzymes in Enterobacter spp. from Brooklyn, New York. 2005;49(2):776-8. consultado: 25/02/2019 Dispoinible en: https://doi.org/10.1128/ AAC.49.2.776-778.200.

16. Boyaca U de. PROTOCOLO BIOCIDAS. Stat $F$ Theor. 2019;53(9):1689-99.

17. Universidad de Boyacá. Protocolo extracción de ADN. Mycol Res. 2002;106(11):1323-30.

18. Chen X, Zhang W, Pan W, Yin J, Pan Z, Gao $S$, et al. Prevalence of qnr, aac(6ロ)$\mathrm{lb}-\mathrm{cr}$, qepA, and oqxAB in Escherichia coli isolates from humans, animals, and the environment. Antimicrob Agents Chemother. 2012;56(6):3423-7. consultado: 15/03/2019. Dispoinible en: https://doi.org/10.1128/ AAC.06191-11

19. Swick MC, Morgan-linnell SK, Carlson KM, Zechiedrich L. Expression of Multidrug Efflux Pump Genes acrAB-tolC, mdfA, and norE in 
Escherichia coli Clinical Isolates as a Function of Fluoroquinolone and Multidrug Resistance. Mechanisms of Resistance 2011;55(2):9214. consultado: 15/03/2019.Dispoinible en: https://doi.org/10.1128/AAC.00996-10

20. Ellappan K, Belgode Narasimha H, Kumar $\mathrm{S}$. Coexistence of multidrug resistance mechanisms and virulence genes in carbapenem-resistant Pseudomonas aeruginosa strains from a tertiary care hospital in South India. J Glob Antimicrob Resist. 2018;12:37-43. Internet: [2018], consultado:30/04/2020 Disponible en: Disponible en: https://doi.org/10.1016/j. jgar.2017.08.018

21. Gotoh N, Tsujimoto H, Tsuda M, Okamoto K, Nomura A, Wada T, et al. Characterization of the MexC-MexD-OprJ multidrug efflux system in DmexA-mexB-oprM mutants of Pseudomonas aeruginosa. Antimicrob Agents Chemother. 1998;42(8):1938-43. Dispoinible en: https://www.ncbi.nlm.nih.gov/pmc/ articles/PMC105713/. PMID: 9687387

22. Jaramillo GI, Pavas NC, Cárdenas JC, Gutiérrez P, Oliveros WA, Pinilla MA. Blattella germánica (Blattodea: Blattellidae) como potencial vector mecánico de infecciones asociadas a la atención en salud (IAAS) en un centro hospitalario de Villavicencio (Meta-Colombia).
Nova. 2016;14(25):19., consultado: Disponible en: consultado: 22/02/2019. Dispoinible en: https://doi.org/10.22490/24629448.1723

23. Cortés JA. Resistencia en enterobacterias: evolución, enzimas y ambiente. Infectio. 2011;15(3):145-6. Internet: [2011], consultado:29/04/2020 Disponible en: http:// www.scielo.org.co/pdf/inf/v15n3/v15n3a01.pdf

24. Tuon FF, Scharf C, Rocha JL, Cieslinsk J, Becker GN, Arend LN. KPC-producing Enterobacter aerogenes infection. Brazilian J Infect Dis 2015;19(3):324-7. Internet: [2015], consultado:22/02/2020 Disponible en: https:// doi.org/10.1016/j.bjid.2015.01.003

25. González Osorio M, Mendoza-Medellín A, Pavón Romero S, Becerril Plata R, Vilchis Quiroz A. Resistencia a cefalosporinas de tercera y cuarta generación en enterobacterias productoras de infecciones nosocomiales y caracterización preliminar de los plásmidos involucrados. Cienc ergo-sum. 2008;15(1):83-90. consultado: 25/02/2019 Dispoinible en: https://dialnet. unirioja.es/servlet/articulo?codigo $=5034962$

26. Yelin I, Kishony R. Antibiotic Resistance. Cell. 2018;172(5):1136-1136.e1. consultado: 28/02/2019 Dispoinible en: https://www.cell. com/cell/pdf/S0092-8674(18)30162-4.pdf 
27. Baucheron S, Tyler S, Boyd D, Mulvey MR, Chaslus-dancla E, Cloeckaert A. AcrAB-TolC directs efflux-mediated multidrug resistance in Salmonella enterica serovar Typhimurium DT104. Antimicrob Agents Chemother. 2004;48(10):3729-35. consultado: 28/02/2019 Dispoinible en: https://doi. org/10.1128/AAC.48.10.3729-3735.2004

28. Masuda N, Sakagawa E, Ohya S, Gotoh N, Tsujimoto $\mathrm{H}$, Nishino T. Substrate specificities of MexAB-OprM, MexCD-OprJ, and MexXYOprM efflux pumps in Pseudomonas aeruginosa. Antimicrob Agents Chemother. 2000;44(12):3322-7. consultado: 06/03/2019 Dispoinible en: https://dx.doi.org/10.1128/ aac.44.12.3322-3327.2000

29. Suarez CJ, Kattán JN, Guzmán AM, Villegas M V. Mecanismos de resistencia Acinetobacter y Enterobacteriaceae y estrategias para su prevención y control. Infectio. 2006;10(2):85-93. consultado: 06/03/2019, Dispoinible en: http://www. scielo.org.co/scielo.php?pid=S0123$93922006000200006 \&$ script $=s c i$. abstract\&tlng $=\mathrm{es}$

30. Wołkowicz T, Patzer JA, Kamińska W, Gierczyński R, Dzierżanowska D. Distribution of carbapenem resistance mechanisms in Pseudomonas aeruginosa isolates among hospitalised children in Poland: Characterisation of two novel insertion sequences disrupting the oprD gene. J Glob Antimicrob Resist. 2016;7:119-25. consultado: 06/03/2019 Dispoinible en: https://doi. org/10.1016/j.jgar.2016.08.007

31. Albornoz E, Lucero C, Romero G, Quiroga MP, Rapoport M, Guerriero L, et al. Prevalence of Plasmid-Mediated Quinolone Resistance Genes in Clinical Enterobacteria from Argentina. Microb Drug Resist. 2017;23(2):177-87. consultado: 06/03/2019, Dispoinible en: https://doi.org/10.1089/mdr.2016.0033

32. Nomoto $Y$, Kubota $Y$, Ohnishi $Y$, Kasahara $K$, Tomita A, Oshime T, et al. Gene Cascade Finder: A tool for identification of gene cascades and its application in Caenorhabditis elegans. PLoS One. 2019;14(9):1-16. Internet: [], consultado: 01/05/2020, Disponible en: https://doi. org/10.1371/ journal.pone.0215187

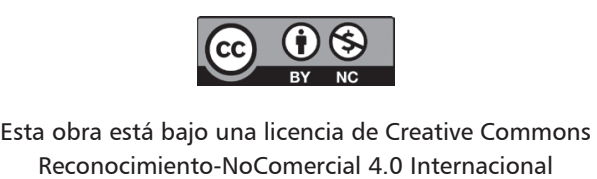

sta obra está bajo una licencia de Creative Commons 